\title{
PENETAPAN KADAR FENOLIK TOTAL DAN AKTIVITAS ANTIOKSIDAN EKSTRAK ETANOL DAUN KOPI KAWA DENGAN METODE DPPH
}

\author{
DETERMINATION OF TOTAL PHENOLIC CONTENT AND ANTIOXIDANT \\ ACTIVITY OF KAWA COFFEE LEAVES ETHANOLIC EXTRACT WITH \\ DPPH METHOD
}

\author{
Aprilia Kusbandari*, Dwi Yogo Prasetyo, Hari susanti \\ Fakultas Farmasi Universitas Ahmad Dahlan, Yogyakarta \\ Jl. Prof. Dr. Soepomo Janturan Umbulharjo Yogyakarta 55164 \\ *Penulis Korespodensi, email: kusbandari80@yahoo.com
}

\begin{abstract}
ABSTRAK
Antioksidan merupakan senyawa yang mampu menghambat laju oksidasi dalam tubuh. Antioksidan sintetik dapat menimbulkan efek samping pada kesehatan tubuh sehingga penggunaan antioksidan alami sebagai pengganti semakin diminati masyarakat karena dipercaya lebih aman. Salah satu golongan senyawa alami yang bersifat sebagai antioksidan adalah golongan fenolik. Daun kopi kawa mengandung flavonoid, alkaloid, saponin, kafein, dan polifenol. Penelitian ini bertujuan untuk mengetahui kadar fenol total dan harga Effective Scavenging (ES) 50 ekstrak etanol daun kopi kawa. Daun kopi kawa diekstraksi menggunakan metode maserasi. Ekstrak kental diuji kandungan fenoliknya dengan reagen FolinCiocalteu dan standar asam galat. Hasil uji kandungan fenolik total dinyatakan dengan kesetaraan asam galat per gram ekstrak (GAE/g ekstrak). Hasil penelitian menunjukkan ekstrak etanol daun kopi kawa memiliki kandungan senyawa fenolik total sebesar 55,87 mg GAE/g ekstrak. Ekstrak etanol daun kopi kawa memiliki aktivitas antioksidan dengan nilai $\mathrm{ES}_{50}$ sebesar $57,79 \mu \mathrm{g} / \mathrm{mL}$ sedangkan untuk standar asam galat memiliki nilai $\mathrm{ES}_{50}$ sebesar $1,54 \mu \mathrm{g} / \mathrm{mL}$. Hasil tersebut menunjukkan ekstrak etanol daun kopi kawa memiliki aktivitas yang kuat sebagai antioksidan.
\end{abstract}

Kata kunci: antioksidan, daun kopi kawa, fenol total, DPPH

\section{ABSTRACT}

Antioxidant is a compound which able to inhibit rate of oxidation in body. Synthetic antioxidants can cause side effects in health so the use of natural antioxidant as a substitute for become favorite one because trusted safer. Phenolic is one of natural compound that is as antioxidant. Leaves Kawa's coffee containing flavonoid, saponin, alkaloid, caffeine, and polyphenol. Research aims to identify the total phenol content and Effective Scavenging (ES) ${ }_{50}$ of ethanol extracts leaves Kawa's coffee.Leaves kawa's coffee extracted uses the maceration. Viscous extract tested its phenolic content with Folin-Ciocalteu reagent and gallic acid standard. Test phenolic content total expressed by gallic acid equivalent per gram extract (GAE/ g extract).The results showed that kawa's coffee leaves 
ethanolic extract has a total phenolic content is $55.870 \mathrm{GAE} / \mathrm{g}$ extract. Leaves kawa's coffee ethanolic extract has antoxidant activity with $E S_{50}$ is $57.972 \mu \mathrm{g} / \mathrm{mL}$ while for gallic acid standard has ES 50 is $1.537 \mu \mathrm{g} / \mathrm{mL}$. The activit of antioxidant extract ethanolic of kawa's coffee leaves is strong.

Keywords: antioxidants, kawa's coffee leaves, total phenol, DPPH

\section{PENDAHULUAN}

Aktivitas antioksidan alami berasal dari metabolit sekunder seperti alkaloid, flavonoid, saponin, tannin dan lain-lain (Ketaren, 1986). Antioksidan golongan fenol memegang peranan penting dalam makanan. Daun kopi mengandung flavonoid, alkaloid, saponin, kafein, dan polifenol. Asam fenolik yang terkandung dalam daun kopi merupakan senyawa antioksidan yang dapat berfungsi menghilangkan radikal bebas di dalam tubuh (Wulandari, 2014).

Mengingat pentingnya fungsi senyawa fenolik sebagai antioksidan maka perlu dilakukan penetapan kadar fenolik total dalam daun kopi kawa. Penetapan kadar fenolik dapat dilakukan dengan menggunakan metode spektrofotometri visibel dengan pereaksi Folin Ciocalteu (Susanti dan Alfian, 2012). Selanjutnya dilakukan pengujian aktivitas antioksidan dapat menggunakan metode DPPH (1,1-Difenil-2-pikrihidrazil (Sashikumar et al., 2009). Parameter yang diamati pada penelitian ini adalah nilai $\mathrm{ES}_{50}$.

\section{METODE PENELITIAN}

\section{Bahan dan Alat}

Bahan yang digunakan dalam penelitian ini adalah daun kopi kawa dari Kabupaten Kerinci. etanol p.a (Merck), $\mathrm{FeCl}_{3}$ p.a (Sigma), aquadest, $\mathrm{NaCl} 2 \%$, gelatin 1\%, ammonia 25\%, kloroform, pereaksi Mayer dan Dragendorf, pereaksi Folin-Ciocalteu (Merck), asam galat (Sigma), aquadest bebas $\mathrm{CO}_{2}$, natrium bikarbonat (JT Baker), DPPH (Sigma-Aldrich).

Alat yang digunakan pada penelitian ini adalah timbangan analitik, pisau, magnetic stirrer, alat-alat gelas, pipet, seperangkat alat spektrofotometer UV-VS pharmaspec UV-1700 Shimadzu.

\section{Jalannya Penelitian}

\section{Pembuatan Ekstrak}

Sebanyak 300 gram serbuk daun kopi kawa direndam dengan etanol 96\% sambil diaduk dengan stirrer selama 3 jam, setelah didiamkan selama 24 jam, disaring dengan corong Buchner dan filtrat yang diperoleh dipekatkan dengan vacuum rotary evaporator.

\section{Uji Skrining Fitokimia}

Uji senyawa polifenol (Harborne, 1987)

Sejumlah ekstrak dilarutkan dalam etanol kemudian ditambahkan pereaksi $\mathrm{FeCl}_{3}$ sebanyak 3 tetes. Terjadinya warna hijau biru menunjukkan adanya polifenol. 
Uji senyawa flavonoid

Sejumlah ekstrak masing-masing dilarutkan dalam etanol, kemudian diteteskan pada kertas saring. Kertas saring tersebut dilewatkan pada uap amonia. Apabila terbentuk warna kuning intensif maka positif mengadung flavonoid (Susanti \& Alfian, 2012).

Uji senyawa alkaloid

Sejumlah ekstrak etanol daun kopi kawa dan standar asam galat masing-masing dengan $5 \mathrm{~mL}$ amoniak 25\% dan digerus dalam mortir lalu ditambahkan $20 \mathrm{~mL}$ kloroform dan digerus kuat. Campuran disaring sehingga diperoleh lapisan air dan lapisan pelarut organik. Lapisan air ditambahkan 2 tetes pereaksi Dragendroff atau pereaksi Mayer. Jika terbentuk warna oranye dengan pereaksi Dragendroff atau terbentuk endapan putih dengan penambahan pereaksi Mayer berarti ekstrak mengandung alkaloid (Anonim, 1979).

Uji senyawa tannin

Sejumlah ekstrak etanol daun kopi kawa dan standar asam galat masing-masing dilarutkan dalam air suling dan dipanaskan selama 30 menit di atas penangas air, kemudian disaring. Filtrat ditambah larutan $\mathrm{NaCl} 2 \%$; bila terjadi endapan, disaring melalui kertas saring. Filtrat ditambah larutan gelatin 1\%; bila timbul endapan menunjukkan adanya tanin atau zat samak (Susanti \& Alfian, 2012).

Uji Pendahuluan

Uji Polifenol

Sejumlah larutan uji dan standar asam masing-masing dimasukkan dalam tabung reaksi, kemudian ditambah dengan 1,5 mL reagen Folin-Ciocalteu. Campuran didiamkan selama 10 menit, lalu ditambah dengan 1,2 mL larutan natrium bikarbonat $1 \mathrm{M}$. Warna larutan diamati secara visual dengan mata (Susanti \& Alfian, 2012).

\section{Uji Antioksidan}

Sebanyak 1,0 mL larutan DPPH dimasukkan ke dalam masing-masing tiga tabung reaksi, kemudian ke dalam masing-masing tabung reaksi ditambahkan etanol p.a, larutan pembanding asam galat, dan larutan uji kemudian diamati terjadinya perubahan warna menjadi kuning (Susanti \& Alfian, 2012).

Uji Fenol Total

Pembuatan Reagen

Pembuatan larutan induk asam galat $(1 \mathrm{mg} / \mathrm{mL})$

Ditimbang sebanyak 10,0 mg asam galat dimasukkan dalam labu takar $10 \mathrm{~mL}$. kemudian ditambahkan dengan $0,5 \mathrm{~mL}$ etanol p.a, kemudian diencerken dengan akuades sampai tanda (Susanti \& Alfian, 2012).

Pembuatan larutan $\mathrm{Na}_{2} \mathrm{CO}_{3} 7,5 \%$

Ditimbang sebanyak 7,5 gram $\mathrm{Na}_{2} \mathrm{CO}_{3}$ ditambahkan $80 \mathrm{~mL}$ akuades, 
kemudian dididihkan sampai $\mathrm{Na}_{2} \mathrm{CO}_{3}$ larut sempurna. Setelah itu didiamkan selama 24 jam, disaring dan diencerkan dengan akuades sampai volume 100 $\mathrm{mL}$ (Susanti \& Alfian, 2012).

Penentuan Kadar Fenol Total (Murtidjaya \& Lim, 2007)

Penentuan kadar fenol diawali dengan penentuan Operating time, pencarian panjang gelombang maximum, pembuatan kurva baku asam galat, dan dilanjutkan dengan penetapan kadar fenolik total.

Uji Aktivitas Antioksidan

Pembuatan larutan DPPH 0,15 mM

Larutan DPPH 0,15 mM dibuat dengan cara melarutkan sebanyak 19,8 mg DPPH dalam etanol p.a hingga $50 \mathrm{~mL}$, diambil $15 \mathrm{~mL}$ selanjutnya ditambahkan etanol p.a hingga $100 \mathrm{~mL}$ (Susanti \& Alfian, 2012).

Pembuatan Larutan Induk Standar Asam Galat

Larutan induk dibuat dari 10,0 mg standar asam galat yang dilarutkan dalam etanol p.a. hingga $10 \mathrm{~mL}$.

Penentuan Panjang Gelombang Serapan Maksimum

Larutan DPPH 0,15 mM sebanyak 1,0 mL ditambah dengan 1,0 mL etanol absolut p.a, kemudian diukur serapannya dengan spektrofotometer UV-Vis pada panjang gelombang 400-800 $\mathrm{nm}$ sampai didapat grafik hubungan antara panjang gelombang $v s$ serapan, dimana serapan tertinggi merupakan panjang gelombang serapan maksimum (Salamah et al., 2015).

Pembuatan Larutan Kontrol Negatif

Kontrol negatif dibuat dari larutan DPPH 0,15 mM sebanyak 1,0 mL yang ditambah dengan $1,0 \mathrm{~mL}$ etanol absolut p.a. kemudian dibaca serapannya pada lamda gelombang maksimum yang didapat pada pengukuran sebelumnya.

\section{Penentuan Operating Time}

Masing-masing standar asam galat $2 \mu \mathrm{g} / \mathrm{mLdan}$ larutan ekstrak etanol daun kopi kawa $1 \mathrm{mg} / \mathrm{mL}$ dalam etanol p.a sebanyak 1,0 mL ditambah dengan 1,0 mL DPPH 0,15 mM, kemudian diukur serapannya pada panjang gelombang $517 \mathrm{~nm}$ selama 0-90 menit sehingga diperoleh waktu serapan yang stabil (Salamah et al., 2015).

\section{Penentuan Aktivitas Antioksidan}

Masing-masing $1,0 \mathrm{~mL}$ larutan induk standar asam galat dengan konsentrasi 0,$2 ; 0,6 ; 1 ; 1,4 ; 1,8 ; 2,2 ; 2,6$ dan $\mu \mathrm{g} / \mathrm{mL}$ larutan ekstrak etanol daun kopi kawa dengan konsentrasi $10 ; 20 ; 30 ; 40 ; 50 ; 60 ; 70 \mu \mathrm{g} / \mathrm{mL}$, ditambahkan 1,0 $\mathrm{mL}$ larutan DPPH 0,15 mM. Campuran dihomogenkan dan didiamkan di tempat gelap sesuai dengan operating time yang diperoleh, kemudian serapan larutan sampel diukur dengan spektrofotometer $U V-V i s$.

\section{Analisis Data}

Analisis data untuk penentuan kandungan senyawa fenolik total dilakukan dengan metode kurva baku, regresi linier $\mathrm{y}=\mathrm{bx}+\mathrm{a}$ dibuat berdasarkan data 
absorbansi dan konsentrasi dari larutan standar. Kemudian dihitung ekuivalensi asam galat (GAE). Aktivitas antioksidan dihitung berdasarkan persen penangkapan radikal dengan menggunakan rumus 1 .

$\%$ Penangkapan Radikal $=\frac{\text { Serapan kontrol-Serapan sampel }}{\text { Serapan kontrol }} \times 100 \%$

Kemudian dilakukan regresi linier antara konsentrasi dengan \%penangkapan sehingga didapat persamaan $\mathrm{y}=\mathrm{bx}+\mathrm{a}$ dimana $\mathrm{y}=50$, sehingga didapat nilai $\mathrm{ES}_{50}$.

\section{HASIL DAN PEMBAHASAN}

Pada pembuatan ekstrak diperoleh rendemen ekstrak etanol daun kopi kawa sebesar 4,87\%. Pada uji skrining fitokimia dilakukan untuk mengetahui senyawa yang terkandung dalam sampel ekstrak etanol daun kopi kawa. Skrining fitokimia yang dilakukan meliputi uji polifenol, flavonoid, alkaloid dan tannin. Hasil uji skrining fitokimia dapat dilihat pada Tabel I.

Tabel I. Hasil skrining fitokimia

\begin{tabular}{cccll}
\hline No & Jenis Uji & Sebelum & \multicolumn{1}{c}{ Sesudah } & \multicolumn{1}{c}{ Kesimpulan } \\
\hline 1 & Uji polifenol & Kuning & Biru kehijauan & Mengandung polifenol \\
2 & Uji flavonoid & Kuning & Kuning intensif & Mengandung flavonoid \\
3 & Uji alkaloid & Kuning & Merah & Sedikit mngandung alkaloid \\
4 & Uji tanin & Kuning & Kuning & Tidak mengandung tanin \\
\hline
\end{tabular}

Penetapan kadar fenolik total menggunakan metode spektrofotometri visibel dengan pereaksi Folin-Ciocalteau. Digunakan pereaksi Folin-Ciocalteau dikarenakan senyawa fenolik dapat bereaksi dengan folin membentuk larutan berwarna biru yang dapat diukur absorbansinya pada panjang gelombang $765 \mathrm{~nm}$. Prinsip metode Folin-Ciocalteau adalah oksidasi gugus fenolik hidroksil. Pereaksi ini mengoksidasi fenolat (garam alkali), mereduksi asam heteropoli menjadi suatu kompleks molybdenum-tungsten (Mo-W). Fenolat hanya terdapat pada larutan basa, tetapi pereaksi Folin-Ciocalteau dan produknya tidak stabil pada kondisi basa.

Selama reaksi berlangsung, gugus fenolik-hidroksil bereaksi dengan pereaksi Folin-Ciocalteau, membentuk kompleks fosfotungstat-fosfomolibdat berwarna biru dengan struktur yang belum diketahui dan dapat dideteksi dengan spektrofotometer. Warna biru yang terbentuk akan semakin pekat setara dengan konsentrasi ion fenolat yang terbentuk, artinya semakin besar konsentrasi senyawa fenolik naka semakin banyak ion fenolat yang akan mereduksi asam hetropoli sehingga warna biru yang dihasilkan semakin pekat (Singleton \& Rossi, 1965). 
Didapatkan hasil kadar fenolik total sebesar 55,870 $\pm 2,90 \mathrm{~g} \mathrm{GAE/g} \mathrm{ekstrak.}$

Tabel II. Hasil uji kualitatif ekstrak etanol daun kopi kawa

\begin{tabular}{|c|c|c|c|c|c|}
\hline Sampel & $\begin{array}{c}\text { Uji } \\
\text { Kualitatif }\end{array}$ & $\begin{array}{c}\text { Larutan sebelum } \\
\text { reaksi }\end{array}$ & $\begin{array}{c}\text { Larutan } \\
\text { sesudah reaksi }\end{array}$ & $\begin{array}{c}\text { Perubahan } \\
\text { warna }\end{array}$ & Keterangan \\
\hline \multirow[b]{2}{*}{$\begin{array}{l}\text { Asam } \\
\text { Galat }\end{array}$} & $\begin{array}{c}\text { Uji } \\
\text { Polifenol }\end{array}$ & & & $\begin{array}{c}\text { Bening } \\
\text { menjadi } \\
\text { biru } \\
\text { kehitaman }\end{array}$ & + \\
\hline & $\begin{array}{c}\text { Uji } \\
\text { Kualitatif } \\
\text { Antioksidan }\end{array}$ & & & $\begin{array}{c}\text { Memudark } \\
\text { an warna } \\
\text { ungu dari } \\
\text { DPPH } \\
\text { menjadi } \\
\text { kuning }\end{array}$ & + \\
\hline $\begin{array}{c}\text { Ekstrak } \\
\text { Etanol }\end{array}$ & $\begin{array}{c}\text { Uji } \\
\text { Polifenol }\end{array}$ & & & $\begin{array}{l}\text { Kuning } \\
\text { menjadi } \\
\text { hijau }\end{array}$ & + \\
\hline $\begin{array}{l}\text { Pisang } \\
\text { Tanduk }\end{array}$ & $\begin{array}{c}\text { Uji } \\
\text { Kualitatif } \\
\text { Antioksidan }\end{array}$ & & & $\begin{array}{l}\text { Memudark } \\
\text { an warna } \\
\text { ungu dari } \\
\text { DPPH } \\
\text { menjadi } \\
\text { kuning }\end{array}$ & + \\
\hline
\end{tabular}

Uji aktivitas antioksidan menggunakan metode penangkapan radikal DPPH (1,1-difenil-2-2pikrilhidrazil). Digunakan metode DPPH dikarenakan metode DPPH merupakan metode yang paling umum digunakan untuk menguji aktivitas antioksidan beberapa senyawa, khususnya senyawa fenolik. Selain itu metode ini cepat, harga terjangkau, teliti, bahannya mudah diperoleh dan alatnya sederhana dan semua tersedia di laboratorium. Pengukuran dilakukan dengan spektrofotometri UV-Vis dengan panjang gelombang $517 \mathrm{~nm}$. Nilai $E S_{50}$ merupakan besarnya konsentrasi senyawa uji yang mempunyai efektivitas penangkapan radikal bebas sebanyak $50 \%$. Nilai $E S_{50}$ standar asam galat dan ekstrak etanol daun kopi kawa berturt-turut adalah $1,537 \mu \mathrm{g} / \mathrm{mL}$ dan $57,87 \mu \mathrm{g} / \mathrm{mL}$. Aktivitas persen penangkapan radikal bebas standar asam galat dan ekstrak etanol daun kopi kawa dapat dilihat pada Tabel III dan IV. Perbandingan nilai $E S_{50}$ ratarata standar asam galat dan ekstrak etanol daun kopi kawa dapat dilihat pada Gambar 1.

Gambar 1 menunjukkan nilai $E S_{50}$ asam galat dan ekstrak etanol daun kopi kawa berbeda signifikan. Nilai tersebut apabila dibandingkan dengan penelitian Cahyani, (2015) yang menyebutkan bahwa nilai $I C_{50}$ ekstrak metanol daun kopi arabika tua dan robusta tua masing-masing sebesar $8,317 \pm 0,050 \mu \mathrm{g} / \mathrm{mL}$ dan 7,519 $\pm 0,029 \mu \mathrm{g} / \mathrm{mL}$ berbeda jauh. Hal ini disebabkan selain perbedaan jenis cairan penyari juga perbedaan daun kopi yang digunakan. Daun kopi yang digunakan sebagai minuman ringan "kawa daun" sedangkan pada penelitian Cahyani adalah daun kopi segar. Aktivitas antioksidan kawa daun ini bila dibandingkan dengan aktivitas antioksidan ampas kopi kawa robusta memiliki 
aktivitas antioksidan sebesar 24,61 \% (Ifwarisan, 2016) memiliki aktivitas antioksidan yang lebih besar juga.

Tabel III. Hasil perhitungan $E S_{50}$ standar asam galat

\begin{tabular}{|c|c|c|c|c|c|c|c|c|c|}
\hline \multirow[b]{2}{*}{ No. } & \multicolumn{7}{|c|}{ Penangkapan radikal bebas (\%) } & \multirow{2}{*}{$\begin{array}{c}\text { Persamaan regresi } \\
\text { linier }\end{array}$} & \multirow[b]{2}{*}{$E S_{50}$} \\
\hline & $\begin{array}{c}0,2 \\
\mu \mathrm{g} / \mathrm{mL}\end{array}$ & $\begin{array}{c}0,6 \\
\mu \mathrm{g} / \mathrm{mL}\end{array}$ & $\begin{array}{c}1 \\
\mu \mathrm{g} / \mathrm{mL}\end{array}$ & $\begin{array}{c}1,4 \\
\mu \mathrm{g} / \mathrm{mL}\end{array}$ & $\begin{array}{c}1,8 \\
\mu \mathrm{g} / \mathrm{mL}\end{array}$ & $\begin{array}{c}2,2 \\
\mu \mathrm{g} / \mathrm{mL}\end{array}$ & $\begin{array}{c}2,6 \\
\mu \mathrm{g} / \mathrm{mL}\end{array}$ & & \\
\hline 1 & 22,78 & 34,62 & 40,52 & 47,60 & 55,15 & 62,11 & 67,62 & $y=18,22 x+21,66$ & 1,55 \\
\hline 2 & 21,58 & 33,57 & 41,00 & 46,64 & 55,27 & 62,23 & 68,58 & $y=18,98 x+20,41$ & 1,50 \\
\hline 3 & 23,50 & 33,33 & 40,88 & 49,40 & 55,99 & 62.11 & 68,46 & $y=18,53 x+21,72$ & 1,52 \\
\hline 4 & 20,62 & 33,45 & 39,80 & 47,36 & 57,07 & 62,23 & 68,94 & $y=19,62 x+19,59$ & 1,54 \\
\hline \multirow[t]{4}{*}{5} & 21,22 & 32,85 & 41,36 & 46,88 & 56,95 & 62,35 & 68,10 & $y=19,21 x+20,20$ & 1,55 \\
\hline & \multicolumn{8}{|c|}{ Rerata } & 1,53 \\
\hline & \multicolumn{8}{|c|}{ SD } & 0,02 \\
\hline & \multicolumn{8}{|c|}{$\mathrm{CV}$} & $0,01 \%$ \\
\hline
\end{tabular}

Tabel IV. Hasil Perhitungan $E S_{50}$ sampel daun kopi kawa

\begin{tabular}{|c|c|c|c|c|c|c|c|c|c|}
\hline \multirow[b]{2}{*}{ No. } & \multicolumn{7}{|c|}{ Penangkapan radikal bebas (\%) } & \multirow[b]{2}{*}{$\begin{array}{l}\text { Persamaan } \\
\text { regresi linier }\end{array}$} & \multirow[b]{2}{*}{$E S_{50}$} \\
\hline & $\begin{array}{c}10 \\
\mu \mathrm{g} / \mathrm{mL}\end{array}$ & $\begin{array}{c}20 \\
\mu \mathrm{g} / \mathrm{mL}\end{array}$ & $\begin{array}{c}30 \\
\mu \mathrm{g} / \mathrm{mL}\end{array}$ & $\begin{array}{c}40 \\
\mu \mathrm{g} / \mathrm{mL}\end{array}$ & $\begin{array}{c}50 \\
\mu \mathrm{g} / \mathrm{mL}\end{array}$ & $\begin{array}{c}60 \\
\mu \mathrm{g} / \mathrm{mL}\end{array}$ & $\begin{array}{c}70 \\
\mu \mathrm{g} / \mathrm{mL}\end{array}$ & & \\
\hline 1 & 12,7 & 21,93 & 25,09 & 33,69 & 45,57 & 53,69 & 60,97 & $y=0,81 x+3,56$ & 56,83 \\
\hline 2 & 9,455 & 17,93 & 26,66 & 35,39 & 42,90 & 48,84 & 56,60 & $y=0,78 x+2,61$ & 60,44 \\
\hline 3 & 10,78 & 19,39 & 28,24 & 36,12 & 44,97 & 51,27 & 61,33 & $y=0,83 x+2,82$ & 56,84 \\
\hline 4 & 12,24 & 19,75 & 29,57 & 34,42 & 46,54 & 54,06 & 61,33 & $y=0,83 x+3,527$ & 55,79 \\
\hline 5 & 10,42 & 20,00 & 27,03 & 34,66 & 44,24 & 49,45 & 56,84 & $y=0,76 x+3,89$ & 59,95 \\
\hline \multicolumn{9}{|c|}{ Rerata } & 57,97 \\
\hline \multicolumn{9}{|c|}{ SD } & 2,08 \\
\hline \multicolumn{9}{|c|}{$\mathrm{CV}$} & $3,59 \%$ \\
\hline
\end{tabular}

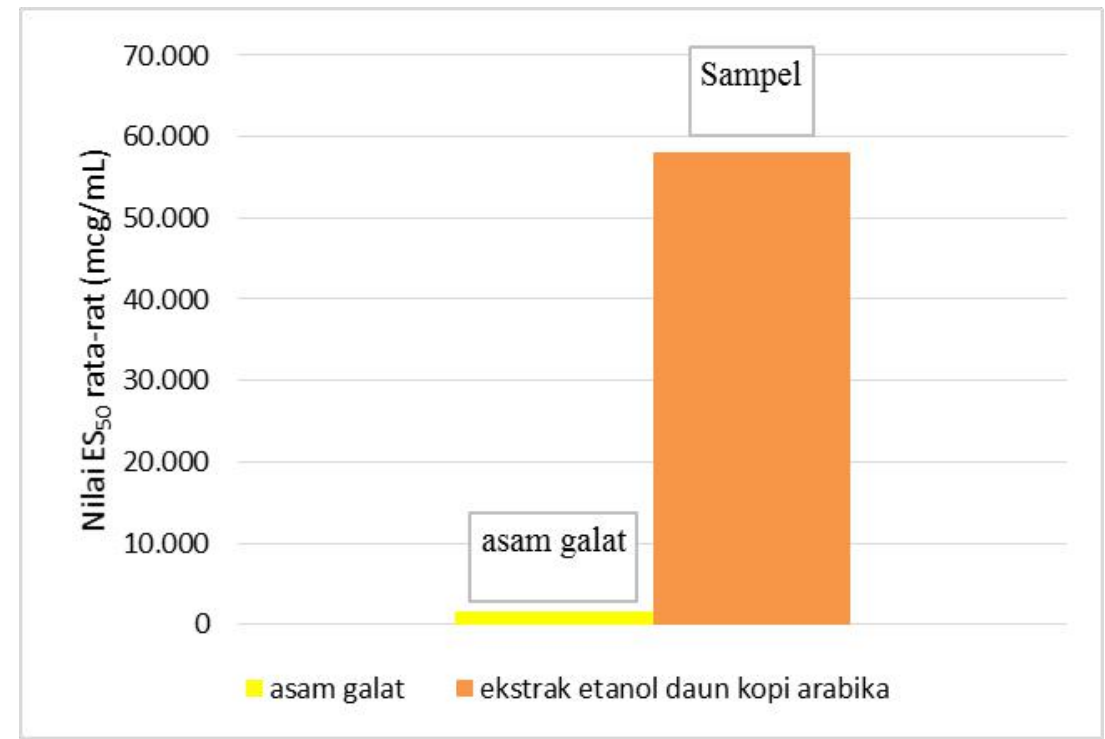

Gambar 1. Nilai $\mathrm{ES}_{50}$ rata-rata asam galat dan ekstrak etanol daun kopi kawa 
Berdasarkan Gambar 1 dapat dilihat bahwa nilai $E S_{50}$ asam galat dan ekstrak etanol daun kopi kawa berbeda signifikan. Nilai tersebut apabila dibandingkan dengan penelitian Cahyani, (2015) yang menyebutkan bahwa nilai $I C_{50}$ ekstrak metanol daun kopi arabika tua dan robusta tua masing-masing sebesar $8,317 \pm 0,050 \mu \mathrm{g} / \mathrm{mL}$ dan 7,519 $\pm 0,029 \mu \mathrm{g} / \mathrm{mL}$ berbeda jauh. Hal ini disebabkan selain perbedaan jenis cairan penyari juga perbedaan daun kopi yang digunakan. Daun kopi yang digunakan sebagai minuman ringan "kawa daun" sedangkan pada penelitian Cahyani adalah daun kopi segar. Aktivitas antioksidan kawa daun ini bila dibandingkan dengan aktivitas antioksidan ampas kopi kawa robusta memiliki aktivitas antioksidan sebesar 24,61 \% (Ifwarisan, 2016) memiliki aktivitas antioksidan yang lebih besar juga.

Jika dibandingkan dengan penelitian Kusmiyati et al., (2015) menyimpulkan aktivitas antioksidan seduhan daun teh hijau sebesar $21,44 \mu \mathrm{g} / \mathrm{mL}$. Penelitian Sudaryat et al., (2015) menyimpulkan aktivitas antioksidan seduhan daun teh hitam sebesar $97 \mu \mathrm{g} / \mathrm{mL}$, dan penelitian Juniarka et al., (2011) menyimpulkan aktivitas antioksidan bunga rosella sebesar 19,991 $\mu \mathrm{g} / \mathrm{mL}$. Maka "kawa daun" masih dapat dijadikan alternatif lain sebagai minuman kesehatan yang berkhasiat sebagai antioksidan.

\section{KESIMPULAN}

Berdasarkan hasil penelitian dapat disimpulkan bahwa kandungan senyawa fenolik total ekstrak etanol daun kopi kawa sebesar $55,87 \pm_{2,90 \mathrm{mg}}$ GAE/g ekstrak. Nilai $E S_{50}$ dalam ekstrak etanol daun kopi kawa sebesar 57,972 $\mu \mathrm{g} / \mathrm{mL}$

\section{DAFTAR PUSTAKA}

Anonim, 1979, Farmakope Indonesia Edisi III, Dearemen Kesehatan RI, Jakarta Cahyani, Y. N., 2015, Perbandingan Kadar Fenol Total dan Aktivitas Antioksidan Ekstrak Metanol Daun Kopi Robusta (Coffea canephora) dan Arabika (Coffea arabica), Skripsi, Fakultas Farmasi Universitas Jember, Jember

Harborne, J., 1987, Metode Fitokimia Penuntun Cara Modern Menganalisa Tumbuhan, Cetakan 2, (K. P. Soediso, Trans.), Penerbit ITB, Bandung

Ifwarisan, D., 2016, PengaruhPerbedaan Lama Ekstraksi Ampas Kopi Kawa Daun (Coffea cannephora) Menggunakan Ultrasonik Bath terhadap Komponen Bioaktif Ekstrak, Skripsi, Universitas Andalas, Padang

Juniarka, I.G.A., Lukitaningsih, E., dan Noegrohati, S., 2011, Analisis Aktivitas Antioksidan dan Kandungan Antosianin Total Ekstrak dan Liposom Kelopak Bunga Rosella (Hibiscus sabdatiffa L.), Majalah Obat Tradisional, 16(3)115-123

Ketaren, S., 1986, Minyak dan Lemak Pangan, UI-Press, Jakarta

Kusmiyati, M., Sudaryat, Y., Lutfiah, I.A., Rustamsyah, A., dan Rohdiana, D., 2015, Aktivitas Antioksidan, Kadar Fenol Total, dan Flavonoid Total dalam Teh Hjau (Camelia sinensis(L.) O. Kuntze) Asal Tiga Perkebunan Jawa Barat, Jurnal Penelitian Teh dan Kina, 18(2): 101-106 
Murtijaya, J., dan Lim Y.Y., 2007, Antioxidant Properties of Phylanthus amarus Extracts as Affected by Different Drying Methods, LWT-Food Sci. Technol, 40: 1664-1669.

Salamah, N., Widyaningsih, W., Izati,I, \& Susanti, H. 2015, Aktivitas Penangkap Radikal Bebas Ekstrak Etanol Ganggang Hijau Spirogyra sp dan Ulva lactuca dengan Metode DPPH (Free Radical Scavenger Activity of Green Algae Ethanolic Extract Spirogyra sp and Ulva lactuca Using DPPH Method), Jurnal Ilmu Kefarmasian Indonesia, ISSN : 1693-1831, 13(2): 145-150.

Sashikumar, J.M., Maheshu, V., Jayadev, R., 2009, In Vitro AntioxidantActivity of Methanolic Extracts of Berbesis Tintoria Lesch.Root and Root Bark, Herbal Medicine and Toxicology 3(2): 53-58

Singleton, V.L. and Rossi, J.A., 1965, Colorimetry of Total Phenolic with Phosphomolybdic-Phosphotungstic Acid Reagent, Am. J. Enol.Vitic, 16.

Sudaryat, Y., Kusmiyati, M., Pelangi, C.R., Rustamsyah, A., dan Rohdiana, D., 2015, Aktvitas Antioksidan Seduhan Sepuluh Jenis Mutu Teh Hitam (Camelia sinensis(L.) O. Kuntze) Indonesia, Jurnal Penelitian Teh dan Kina, 18(2):95-100

Susanti, H., Alfian, R., 2012, Penetapan Kadar Fenolik Total Ekstrak Metanol Kelopak Bunga Rosella Merah (Hibiscus sabdariffa Linn) dengan variasi tempat tumbuh secara Spektrofotometri,„Jurnal Ilmiah Kefarmasian, 2 (1): 73-80

Wulandari, A., 2014, Aktivitas Antioksian Kombucha Daun Kopi (Coffea arabica) dengan Variasi Lama Waktu Fermentasi dan Konsentrasi, Ekstrak, Skripsi, Universitas Muhammadiyah Surakarta, Surakarta 